\title{
Do Metaphors Affect Economic Theory? ${ }^{i}$
}

\author{
by \\ Maurice Lagueux \\ Université de Montréal
}

Over the last few decades, theoretical discussions about metaphors have appeared with increasing frequency in the literature and, during the last fifteen years or so, such discussions have became more and more common in the methodology of economics. But what exactly is a metaphor? According to a tradition which dates back to Aristotle, ${ }^{\text {ii }}$ a metaphor is the attribution to one object, A, of the name (and indirectly of the qualities) of another object, B, while this name or these qualities do not properly or normally belong to A. Thus, a metaphor is present when a term used to describe (or even to name) A is a term which is already commonly used to name B (quite a different kind of entity). Defined in such a way, one must admit that metaphors are frequently found in economics as well as in other sciences. Let us consider, for example, a term like "elasticity" which is extensively used by economists. According to the ordinary dictionary definition, this word designates a property of bodies by which they recover their initial form after having been submitted to a pressure; in a less technical sense, it refers to the flexibility of some bodies or to their responsiveness to pressures. Thus, Marshall was resorting to a metaphor when, in his analysis of demand (which is far from being a body), he used the term to describe the property according to which "the amount demanded increases much or little for a given fall in price, and diminishes much or little for a given rise in price" (Marshall, 1920, p. 86). It is through semantic transfers of this kind that the vocabulary of the various sciences have been progressively extended with the help of metaphors. 
The abundance of such examples of metaphors in economics (equilibrium, friction, liquidity, circulation, depression, etc.) has been strongly emphasised by Donald McCloskey in The Rhetoric of Economics. ${ }^{\text {iii }}$ This new interest in metaphors in economics was preceded by twenty years of considerable attention to the topic among philosophers and literary critics. One of the most influential contributions to the analysis of metaphor was made by the philosopher Max Black who developed what he called the interaction view of metaphor. According to this view, a metaphor is an interactive process involving both a "principal subject" and a "subsidiary subject". In this process, the latter is projected on the former and the two are associated with each other by what Black calls a "system of implications". (Black, 1962, pp. 38-47) The two domains which are put into relation this way are described as influencing each other in such a way that each one becomes "a lens for seeing the other". iv According to this view, our way of seeing elastic bodies as well as demand would be changed in some fashion through the adoption by economists of the word "elasticity" to describe demand sensitivity to prices. It is this approach to metaphors that explicitly inspired McCloskey, especially in his discussion of Gary Becker's metaphorical system of concepts associated with human capital: "In the phrase 'human capital' the field in economics treating human skills was at a stroke unified with the field treating investment in machines. Thought in both fields was improved[...]" (McCloskey, 1985, p. 77). Be that as it may, metaphors being only one among various devices resorted to by traditional rhetoric to persuade people by making ideas more attractive, McCloskey invoked a host of various kinds of examples to develop the thesis according to which economics is a rhetorical enterprise akin to literature and poetry. This emphasis on the literary character of economics looked so convincing in the circles influenced by McCloskey's view that it became more and more common to characterise economic 
theories as narratives - a genre in which the use of metaphors seems to be quite congenial - or more simply as stories, which are normally said to be "good" or "bad" rather than true or false. In any case, whatever its links with storytelling and even with other tropes resorted to by traditional rhetoric, the notion of metaphor understood in a relatively broad sense became a kind of banner for this rhetorical movement.

It was in this context that Philip Mirowski published his oft-cited book More Heat than Light denouncing the way neoclassical economics, according to him, was born from the borrowing of the whole theoretical structure of XIXth century energetics." Without endorsing all McCloskey's claims, Mirowski presented this systematic application of a conceptual structure borrowed from physics to economics as the founding metaphor of neoclassical economics. Given the fact that Mirowski did substantial albeit controversial work to document his thesis, the very idea that metaphor was a fundamental but suspicious element in the constitution of economics was considerably reinforced. Typically enough, when Arjo Klamer and Thomas C. Leonard in a paper devoted to the nature of economic metaphors referred to "constitutive metaphors", characterised by them as the most fundamental type of metaphors met in economics, they turned to the central metaphor discussed in More Heat Than Light to illustrate what they meant (Klamer \& Leonard, 1994, p. 41). Be that as it may, during the nineties, the idea that metaphor is the key element of economic theories has apparently gained considerable audience among a number of methodologists of economics who seem to feel comfortable with the idea that economic theories are nothing but extended metaphors born from the attribution to economic objects of qualities and structures previously pertaining to different contexts. 
If all this were the case, economic theory would face a serious problem that can be put in the following way. Traditionally, an economic theory was seen both as a rational and precise explanation of a phenomenon and as an explanation which could be criticised on logical and empirical grounds; ultimately, it makes sense to test a theory in order to make a judgement about its truth or falsity. It is not as clear that metaphors can be criticised on a logical basis or be put to the test. More precisely, they tend to discourage attempts to discuss them on the basis of logical or empirical analyses and, for this reason, it hardly sounds reasonable to declare them either true or false. It would be odd, for example, to test whether it is true or false that the working of the market is guided by an invisible hand - possibly the most venerable metaphor associated with an economic theory - just like it would be absurd to test the truth or falsity of the proposition according to which Adam Smith is the father of economics. While metaphors of this kind can be evaluated on various grounds (aptness, relevance, clarity, insightfulness, etc.), the point is that in such an evaluation considerations based on logic and on empirical adequacy tend to be overshadowed by considerations related to rhetoric (are they persuasive?) and to literary quality (are they good stories?). We will see later in this paper that even when their metaphorical content is acknowledged, theories can still be tested for what they are, but once theories are more or less assimilated to metaphors, it is tempting to conclude that, even if they provide suggestive explanations of phenomena, it would be totally inappropriate to assess them purely on a logical or empirical basis.

One could object that metaphors might have a useful role in economics as pedagogical or heuristic devices without discrediting theories which are quite different animals: theories aim to say exactly what things are whereas metaphors only give an idea of the structure of these things by referring to something else which is structurally 
comparable. But such a distinction would be deceptive, since theories - even theories in the natural sciences (see Hesse, 1972 and Cartwright, 1983) - do not say exactly what things are. For example, it is far from being literally true that consumers are units which always decide by maximising their utility or that firms are units which are managed in such a way that their marginal revenue is equated to their marginal costs. Just like the various hydraulic and electronic analogies which have been devised to illustrate "metaphorically" their main principles, economic theories help us to better understand some structural features of consumer behaviour or of competitive markets but in no way do they describe exactly the way things are.

But if this is the case, what is the difference between theory and metaphor? Moreover, if metaphors are so pervasive in the theoretical language of economics and if economic theories are not radically different from analogical models which are commonly said to be "metaphorical", what is left of the methodological claims which are usually associated with scientific theories? According to those who have associated themselves with the rhetorical movement, the "metaphorical" character of economics should considerably affect our methodological views about theories. Indeed, for McCloskey, there is no point in developing any methodological analysis of economics because rhetoric, which "deals with conversation", is "a better way to understand science" (1985, p. 28), given that "good science is good conversation" (1985, p. 26) or even genuine poetry. Defending similar views, Klamer and Leonard do not hesitate to blame "scientific minded economists" who are offended "when McCloskey equates economics with poetry because it too relies on metaphors" (1994, p. 20); according to them, the pervasive and subversive character of metaphors in economics should force economists to adopt an attitude quite different from those suggested by most philosophers of economics. In fact, in the writings of the rhetorical school, it is difficult 
to identify what could count as technical arguments against the most common methodological theses about economics. Rather, what seems to be prevalent in this literature is the idea that, once the significance of metaphors is fully acknowledged, maintaining those methodological theses becomes pointless since they must finally give way to more relevant literary and rhetorical considerations.

It is this claim that I would like to challenge. While a comprehensive analysis of the rhetorical school approach should discuss its views on the role of narratives and of various other ways to persuade in economics, the present paper will be limited to challenging this claim to the extent that it rests on the importance of metaphors in economics. Towards this end, I will argue that such a claim loses its relevance when one considers (1) that everything which is not to be clearly understood literally is not necessarily metaphorical, (2) that almost all metaphors used in economics are dead metaphors which no longer work as metaphors, and (3) that so-called metaphors must be clearly disentangled from explicit analogies which are methodologically much more acceptable. Before taking sides against the rhetorical challenge of conventional methodological theories I must add, however, that I am fully aware that standard questions concerning truth, objectivity, explanation and proof raise considerable epistemological problems which have been extensively discussed in the context of scientific theory in general, whatever its metaphorical content. It is not my aim in this paper to speak to these epistemological problems nor to deny their importance. Instead, I wish to make the far more limited claim that very little is added to them when the metaphorical character of theories are brought into the picture. Similarly, my intention is not to deny the existence of significant epistemological differences between the natural and social sciences, but since metaphors are present in both, I maintain that such differences are not linked to the presence of metaphors as such. 


\section{This is not a metaphor}

Let us consider more carefully what the claim of those who emphasise the pervasiveness of metaphors in economics consists in. For example, Klamer and Leonard observe that "the most celebrated metaphor in economics" is a Marshall cross representing, for example, a labour market (Klamer \& Leonard, 1994, p. 23). While it is a bit odd to present as a metaphor what is a representation rather than an utterance, these authors are right to suggest that Marshall's way of representing the interaction in a market of buyers' and sellers' respective propensities with the help of two intersecting curves can generate utterances which can hardly be called "literally true". For example, the sentence "Here, we have our market for labour" spoken by an economist in reference to a cross on a blackboard can hardly be true if each word is taken in its literal sense since there is a cross on the blackboard but not a market. To be sure, this cross is materially quite different from the market that it represents, but is any such representation necessarily metaphorical? And in what sense exactly should this sentence be taken non literally? Answering these questions requires some clarification of the meaning of both literalness and representation.

Defining the word "literal" is not an easy thing. The philosopher John Searle (1979, p. 94) has gone so far as to claim that "to give an accurate account of literal predication is an extremely difficult, complex, and subtle problem". According to the Oxford English Dictionary, this word - if we ignore the meanings which do not apply to the present context - originates in theological exegesis where literal interpretations 
were opposed to mystical or to allegorical ones. More commonly, it refers to the relatively primary sense of a word "as distinguished from any metaphorical or suggested sense". Thus, the word can hardly be defined otherwise than by excluding what is metaphorical and, one must surely add, what is dependent on other tropes. For example, an understatement, an exaggeration or an ironical utterance must not be literally understood. In a less indirect fashion, the word "literal" might tentatively be defined as referring to the primary sense of an utterance or as referring to the purely conventional meaning of the words (see Sadok, 1979). In any case, various authors have underscored the fact that there is no hard and fast boundary between "literal" and "metaphorical" (Sadok 1979; Rumelhart, 1979; Cornell Way, 1991, ch. 1). There is so little hope to give to the word "literal" a standard definition that Eileen Cornell Way concludes her analysis of the question by claiming: "The function of 'literal' is not to contribute positively to the characterisation of anything, but to exclude possible ways of being non-literal." (Cornell Way, 1991, p. 20)

If such is the case, it becomes difficult to decide whether or not a representation that is not associated with tropes should be taken literally. If one represents the orbit of a planet with the help of an ellipse on a blackboard, it seems reasonable to say that one represents it literally. Let us note however that, in this case, the ellipse on the blackboard does not solely represent but rather exemplifies an ellipse: the drawn ellipse is literally an ellipse, it has the essential features of an ellipse, whereas the cross does not in the same sense exemplify a market. In fact, the ellipse is an abstract entity which can be materialised in a drawing, but this is far from being typical of most representations. For example, a material object which is represented by its image is not exemplified in the same sense by this image. This situation is at the source of the paradoxical inscription "This is not a pipe" that the painter Magritte 
placed at the bottom of his famous painting unequivocally representing a pipe. Indeed, by contrast with the representation of the ellipse, the image of the pipe does not exemplify what it represents and does not possess the most essential feature of a pipe, namely the capacity of being used to smoke ${ }^{\text {vi }}$ But the notion of representation is still more complex. Let us consider a map on which a mountain is represented through a set of contour curves. Since many features (size, matter, colour, etc. ) of the set of curves are totally different from the corresponding features of the mountain represented, this set of curves does not exemplify a mountain or, if one prefers, literally speaking is not a mountain. However, some of its features exemplify some features of the actual mountain, in particular the curves on the map exemplify the kind of curves which are running at constant levels of the mountain. Therefore, while it would not be literally true to say that the set of curves on the map is a mountain, it might be literally true to say that these curves have been designed in such a way that their shapes are more or less exactly the same (at a different scale) as those of the curves running at various levels of the mountain.

The Marshall cross corresponds to a still more complicated case of representation. The crossing curves represent a market, but it does not seem possible to say that any feature of the cross exemplifies any single feature of the market. More precisely, the curves represent respectively propensities to buy or to sell according to a given price, but they do not exemplify such propensities. At most, one could possibly claim that it is literally true that a specific mathematical relation between the (vertical and horizontal) positions of each of their points on a graph exemplify the complex relation which prevails between prices and (indirectly) observed propensities to buy or to sell at such and such a price. Given the complexity of such a relationship, it is understandable that one is tempted to say that standard utterances referring to such a 
cross should not be taken too literally. However, even if a comparison - in this case, between some properties of geometrical figures and those of trader's propensities - is involved, in all these cases of representation, there is, strictly speaking, no metaphor (nor even metonymy), unless one refers to the set of contours as if it were a mountain or to the cross on the blackboard as if it were a market. In fact, economists often refer to the "law of downward sloping demand" or claim that "the demand moves to the right" as if the demand itself had the properties of a geometric figure. Such utterances are clearly metaphorical since they attribute to demand features pertaining to geometric curves, but it is not the cross as a geometrical representation that is a metaphor. At most, given the boldness of the implied comparison between the respective properties of the cross and those of the market, one can speak of a "metaphor", but only in the broad sense of the word that is often harmlessly used in contexts where the important distinction between metaphor and comparison is not relevant. Be that as it may, since it would involve an unproductive and absurd acrobatics for economists to restrain themselves to words taken in their most primitive and conventional sense and to restrict themselves to using complex sentences which could be said to be literally true in the sense illustrated above, Klamer and Leonard have no trouble suggesting that most significant claims of economists should not be taken literally. And since they tend to characterise as metaphorical anything which is not literal, they have no trouble suggesting that economics is full of metaphors and that it is at best "metaphorically" true.

In fact, members of the rhetorical movement tend not only to find a metaphor in each case of an utterance that can not be characterised as unequivocally literal but also to conflate the use of metaphors and that of abstract concepts. For example, when it comes to explaining that "economics itself 'leaves out' some features of the truth" 
(McCloskey, 1985, p. 82), McCloskey attributes this fact to metaphors since they emphasise only a selection of traits. Even if it is common to attribute such a reductive selection of traits to the process of abstraction necessarily engaged in by economists, McCloskey typically enough prefers to detect a metaphor, a trope usually associated with literature and poetry rather than invoking abstraction, a process usually associated with scientific research. For their part, Klamer and Leonard say that "Space is Euclidean and can be thought of only with the metaphor of lines and points..." (Klamer \& Leonard, p. 40), but it is difficult to see in what sense space and lines have to be understood metaphorically in a Euclidean context. It is true that Euclid, when referring to pure lines (that is, lines without breadth), did not refer to the type of lines that people ordinarily have in mind, but it is in no way with the help of a metaphor borrowed from another area of knowledge that he has forced the usual meaning of the word "line" to construct an abstract concept. It is correct to oppose "metaphorical" to "literal", but this opposition is not the same and so should not be confused with the opposition between what is abstract and what is concrete. After all, if by "metaphors" one loosely refers to standard ingredients of any scientific theory like representation, idealisation and abstraction, no one would have any reason to be bothered by the fact that "economics is full of metaphors".

\section{Dead Metaphors in Economics}

Thus, if the word "metaphor" were itself taken in a more "literal" sense, then metaphors would be perceived as much less pervasive in economics, but this is not to say that they are not present and even abundant. But what are the implications of this fact and to what extent do these implications have a subversive impact on economics? According to Klamer and Leonard, the most crucial implications arise when, alongside 
pedagogical and heuristic metaphors, we refer to what they call "constitutive" metaphors which frame our very way of thinking. When it comes to exploring an unknown domain, one has to resort to conceptual schemes which are often borrowed from a more familiar sector of knowledge. Since these conceptual schemes will tend to frame, and consequently to influence decisively the whole development of the analysis of this domain, the authors characterise them as "constitutive", and since they tend to classify as metaphorical any borrowing of conceptual schemes, they call them "constitutive metaphors". After presenting Mirowski's "energetic metaphor" as possibly the most significant constitutive metaphor, they claim that "metaphors" of this type can frame our way of thinking and suggest to us ways of organising ideas and forging new categories. To substantiate their point, they refer to Stephen Pepper's four "world hypotheses", each of which is based on a "root metaphor": organicism, mechanism, formism and contextualism, respectively. ${ }^{\text {vii }}$ According to Klamer and Leonard, tracking down the metaphorical origin (organicist, mechanicist or otherwise) of interpretations adopted by economists could be significantly helpful in clarifying the source of some of the disagreements between them. It is true that one could object that such an analysis could hardly be of great help with respect to fundamental epistemological disagreements about the proper way to assess theories; however, let us admit that the authors have in mind nothing other than disagreements about the proper way to conceptualise economic phenomena.

To get a better handle on the implications of this approach, let us consider the case, documented by Timothy Alborn (1994), of a situation which seems to correspond to such a disagreement generated by conflicting metaphors. Alborn describes the conflation in Victorian monetary economics of a biological image (the circulation of blood in the body) and a mechanical one (that of steam in an engine). Everyone agrees 
that money circulates in the economy, but depending on the way we think of it circulating, either like blood or like steam, we can be driven towards quite different conclusions. ${ }^{\text {viii }}$ But this situation is not overly dramatic, since we may simply consider that money actually circulates neither like blood nor like steam but like money. An immediate objection to this consideration would be that money does not circulate at all except metaphorically, and that this "metaphor", as illustrated by Alborn's paper on Victorian economics, is either organicist or mechanicist. After all, money is not a fluid which could literally circulate through veins or pipes. It is true that we frequently refer to "liquid money", but this is even more clearly metaphorical, so clearly so, in fact, that as Klamer and Leonard observe, we do not feel threatened by the idea that liquid assets might be frozen when transported to Alaska (1994, p. 23). However, if this consideration illustrates fairly well that the expressions "liquid money" or "liquid assets" have a metaphorical origin and that they should not be taken "literally", it also illustrates that the metaphor from which it originates is at present totally dead and that the sentence no longer works metaphorically. The very fact that no economist would be naive enough to have in mind any kind of genuine liquid when referring to liquid assets shows that the word "liquid" has been given a new (economic) meaning. Similarly, the word "circulation" has a very long time ago received a larger meaning according to which "taking different forms and being successively owned by different persons until returning to a similar position" is a perfectly acceptable way to circulate. Consequently, money no longer circulates metaphorically; it circulates literally.

If this were not the case, then one would have to claim that water circulates metaphorically as well. Indeed, we do not need to push the etymological analysis very far to discover that "to circulate" means "to describe a circle". But water almost never describes circles when it circulates; therefore it circulates only metaphorically. 
However, to say that water circulates or to say that money circulates is, in both cases, to use a word born of one of those dead metaphors which are at the source of innumerable standard words of any language. If they wanted to suggest that theories should not be taken literally, Klamer and Leonard overshoot the mark, because the metaphorical language they refer to is so pervasive that it corresponds to a rather common language that cannot significantly be contrasted to a less metaphorical one. Like so many utterances in everyday language which can be declared metaphorical in this loose sense for being associated with a dead metaphor, these economic utterances have to be understood literally, because, in such conditions, to understand by virtue of a (dead) metaphor is more or less the same thing as to understand literally.ix As Max Black said: "A so-called dead metaphor is not a metaphor at all, but purely an expression that no longer has a pregnant metaphorical use. A competent reader is not expected to recognise such a familiar expression as "falling in love" as a metaphor, to be taken au grand sérieux. Indeed, it is doubtful whether that expression was ever more than a case of catachresis (using an idiom to fill a gap in the lexicon)".. Since such dead metaphors have become fully-fledged parts of plain language, it is not with literal utterances that they should be contrasted but rather with live metaphors.

Thus, the next question to raise is: "What would it imply for a metaphor to be live and not dead?" A metaphor is live when, to use Nelson Goodman's apt characterisation, it can "be regarded as a calculated category-mistake". ${ }^{\mathrm{i}}$ Alternatively, one can say with Monroe Beardsley that a live metaphor involves a kind of "logical opposition" which shocks the reader and contributes to the creation of a new meaning (1972, pp. 73-91). A live metaphor has to do violence to common meanings and describe a phenomenon in a shocking fashion, using categories normally applicable only to quite different phenomena. Thus poetic metaphors are typically live. When one 
reads the Odyssey, one still visualises rosy fingers, almost three millennia since Homer first described dawn with the help of this metaphor. This metaphor was a strange and not very logical way to emphasise the beauty of something which could have been designated otherwise (pink strips in the sky visible at dawn) but whose concrete richness and magnificence is too quickly forgotten without the help of such a metaphor, which continues thus to be live after centuries. At a much less poetical level, when an advertisement says that I should "put a tiger in my tank", the metaphor is live because "tiger" is not yet the standard name of a kind of gasoline, but it rather points to an unexpected association which is deemed to be appealing enough to capture the imagination of drivers. By contrast, most economic metaphors are dead metaphors because they are nothing but practical ways of designating phenomena which could not be designated in more literal words, such as a particular form taken by money (liquidity) or the phenomenon by which money, through free exchange, is able to return to its original point (circulation). Once the new name is accepted and integrated into the common parlance of economists, the metaphor is quickly forgotten and the phenomenon is understood for what it is. When economists refer to liquid money, they do not refer to a substance similar to water; when they refer to the circulation of money, they do not mean that money flows inside pipes or veins. Consequently, it can be literally true or false that money circulates in the economy because the question at hand is whether it circulates (according to the only meaning appropriate for money) or not.

Thus, since statements made with the help of such dead metaphors can be literally true or false, jut like statements made with words in their literal sense, it is difficult to see why the metaphorical origin of economic categories can force us to revise in a significant way our understanding of the nature of a theory. But what about 
live metaphors met in economics? Let us acknowledge to begin with that they are much less abundant than dead metaphors. Most of the examples quoted by McCloskey or by Klamer and Leonard (capital, liquidity, elasticity, inflation, depression, accelerator, multiplier, etc.) are clearly dead metaphors which, in the mind of economists who use them, are understood as technical words and unambiguously defined as if they were not metaphorical at all. In fact, there is a reason for the shortage of live metaphors in the list provided by these authors. Metaphors which would avoid dying as metaphors by being not integrated in the basic vocabulary of economics would be incidental metaphors emanating from the colourful imagination of an economist. When, for example, an economist refers to the voracity or to the "long teeth" of an aggressive entrepreneur, he is clearly using live metaphors but these metaphors would not be representative of economics as a science and would be quite inessential to the structure of economic theories. Consequently, such metaphors would be quickly forgotten by contrast with Homer's "rosy fingers" which is an essential element of a great piece of poetry. ${ }^{\text {ii }}$ Apparent exceptions to this rule are Smith's "invisible hand" and Keynes's "animal spirits". Both are live metaphors that are still as evocative as literary metaphors, but, being metaphors of this type, they are not ingredients of economic theories as such. There is no longer room for an invisible hand or for animal spirits when it comes to exposing technically the theory of a competitive market or the theory of the marginal efficiency of capital. Either metaphorical terms play a significant role in economic theories, but then they are dead metaphors which no longer have, to use Black's words, "a pregnant metaphorical use" or they are live metaphors and they are perfectly dispensable from the point of view of economic theory.

A more complicated case is that of the concept of human capital whose "metaphorical" application to children by Gary Becker was taken as a sort of 
paradigmatic example by Klamer and Leonard (1994, pp. 32-33) as well as by McCloskey (1985, pp. 74-79). An example equally to the point is the application by the same economist of the market concept to various sociological situations like the choice of partnership in marriage and the determination of the number of children, which incidentally offers a case of exportation of economic concepts towards other sciences by contrast to the importation referred to by Mirowski. Be that as it may, given the still controversial character of Becker's view within the academic community, it would be difficult to claim that these "metaphors" are nothing but dead metaphors filling a gap in the common vocabulary; nonetheless they play a crucial role in Becker's theory. Before discussing this case, however, we must consider the difference between metaphors and analogies and the relation between analogies and economic models.

\section{Models, Analogies and Metaphors}

If economists who are acquainted with these methodological debates seem not to have been disturbed by the widespread reference to metaphors in recent literature, it is largely due to the fact that they are accustomed to models even more than to theories. In fact, economists have in mind the theoretical models that they use to represent some structural aspect of the economic world. ${ }^{\text {xii }}$ For example, they refer to models of the firm or to general equilibrium models. Through such theoretical models, economists represent, in a more or less schematic fashion, interrelations which they consider significant for the understanding of a sector of the economic world. They do not pretend that such models depict faithfully what is going on in this world. They do not pretend that flesh-and-blood entrepreneurs systematically hire or fire workers any time such moves allow their marginal cost to come closer to their marginal revenue. Some methodologists would even say with Daniel Hausman that models in the sense given to 
this word by economists "are definitions and are constituted by sets of assumptions" (Hausman, 1992, p. 75). According to Hausman, it is even "a category mistake to ask whether they are true or to attempt to test them" (1992, p. 78). One can disagree with Hausman's radical view on this point, but it remains somewhat ambiguous to declare plainly true or false so many economic models which have been designed to explore conceptual relations like those involved in a general equilibrium on a highly theoretical kind of market. From this point of view, such models share with metaphors the character of being not immediately reducible to literal assertions about the world. It is true that, at some point, economists will normally apply them to the relevant sector of the world, but this will be done only with the help of supplementary hypotheses whose role it is to adapt the model to such an application. The fact that such economic models are not taken as literal assertions about the world is made still more manifest when one considers that some economists have developed electronic or hydraulic models in order to visualise structural relations which are equivalent to those highlighted by these theoretical models. Models of this kind, which provide a concrete image of the abstract relations involved and which therefore are sometimes called "iconic" models, have often been presented as "metaphorical" interpretations of the theory. ${ }^{\text {iv }}$

To make the present discussion more concrete, let us consider an "iconic" (or "analogue") model of this type which has been constructed by a well known economist. A. W. H. Phillips designed an hydraulic model in order to illustrate his Keynesian approach to a theory of monetary flow (Phillips, 1950). At first glance, this model seems to have properties similar to those of a metaphor. However, when discussing the analogy on which it is based, the question at hand is clearly not whether it is true or false that the money involved in repeated exchanges is nothing but water flowing through pipes, but rather whether it is sensible to compare the circulation of money to 
the circulation of water. But is it appropriate to treat such models as metaphors? Strictly speaking, they are not metaphors, but analogical constructions. But are not analogies metaphors of some kind? Klamer and Leonard claim that they are; according to them, an analogy is "a sustained and systematically elaborated metaphor" (1994, p. 45). Before them, Mirowski also blurred the differences between metaphors and analogies. Indeed, in More Heat than Light, to illustrate that "scientific reasoning is metaphorical", he found it appropriate to quote Duhem saying that "the history of physics shows us that the search for analogies between two distinct categories of phenomena has perhaps been the surest and most fruitful method of all the procedures put into play in the construction of physical theories." (quoted by Mirowski, 1989, p. 277-278, my emphasis). But Duhem chose the word "analogies" because analogies are not metaphors. Analogies can be defined as sustained similes but not as "sustained metaphors". When a metaphor is "sustained", one should rather refer to it as an allegory. ${ }^{\mathrm{xv}}$ An analogy is to a simile what an allegory is to a metaphor. A metaphor is the attribution to one object of the name (or the qualities) of another whereas an analogy is an explicit comparison (a sustained simile) between two domains, a comparison that has the virtue of pointing out a range of functional similarities between the two domains. Far from indulging in a "calculated category-mistake" or doing violence to logic, the author of an analogy systematically underscores the respective characters of these two domains in such a way that their distinctiveness is explicitly preserved. These distinctions between metaphor, simile, allegory and analogy are important because whereas metaphors and allegory are poetical and essentially suggestive literary tropes, simile and analogy are analytic exercises which are perfectly suited to scientific analysis. ${ }^{\text {xvi }}$ When the question at stake concerns the nature of theories - their openness to logical criticism, testing and verification or falsification - it is important to keep in mind that associating theories with metaphors might sound 
much more dangerously subversive than associating them with similes or analogies. By violating what logic requires, a genuine or live metaphor attributes to an entity properties which do not normally belong to it, whereas an analogy is an explicit and systematic comparison between two different entities.

For example, a valve in an hydraulic model can play a function similar to that of a price increase in economics: both will tend reduce the flow either of water or of money. ${ }^{x v i i}$ No doubt that such analogies - as is the case with so many linguistic operations - imply metaphors and, as we can see in this example, analogies can be built by awakening dormant metaphors like the one from which the word "flow" as used in economics was born. Since the very notion of a "flow" of money has a metaphorical origin, why not check whether or not the mechanism which explains the behaviour of money is functionally similar to the mechanism which explains the behaviour of water in a system with comparable constraints? As we have seen, it is these kinds of analogies that are made manifest by analogical models (hydraulic, electronic, etc.) which, like mathematical theoretical models, analyse mechanisms potentially at work in the real economic world. Taken as a whole, such models clearly rest on an analogy but not on a metaphor. Indeed, they do not indulge in the calculated category-mistake which consists in saying (in a doubtfully poetical language) that money is conducted through pipes and valves to a reservoir of wealth. Instead, these models result from a particularly explicit comparison between the mechanism suspected to be at work in the economic world and the one at work in the hydraulic machine involved.

It is true that analogy, in the case of some theoretical models, is used as a tool to explore structural relations in a phenomenon. And since all the features which are 
common to both sides of the analogy are not given in advance, such a tool should not be considered dispensable. Indeed, a number of these features cannot be known before the structure of one domain is applied to the other and this cannot be accomplished in absence of some conceptual violence. It is for this reason that Black argues that such models are based on metaphors involving the interaction of two structures rather than on analogies reducible to comparisons between two previously known structures. ${ }^{\text {xvii }}$ According to McCloskey, (1985, pp. 74-79) a case in point in economics is the bold development by Gary Becker of the analogical potential of Theodore Schultz's famous "human capital" metaphor. It is true that all the structural features of capital which can be compared to those of children were not known in advance and McCloskey was probably right when he observed that, thanks to a Blackian interactive process, thought was improved both in labour economics and in capital theory. (1985, p. 77) It is also true that the human capital metaphor never really died as a metaphor because its emotional content remains shocking for most people, but what else can we conclude from this? Once the various features of children that are comparable to those of more typical durable goods have been spelled out by Schultz and later by Becker (and judged disappointing by many of the theory's critics), it was a systematic analogy between durable goods and human beings which was modelled to become the inspiration of the human capital theory. A theoretical model was designed with the help of a relatively new conceptual apparatus according to which children are a kind of durable goods, just like "labour forces" were a kind of saleable goods grown in families in Marxian models. Becker does not say that flesh-and-blood parents always take their decisions concerning children on the basis of a cost-benefit analysis, nor was Marx naive enough to say similar things about workers' families, nor have marginalist economists said that actual consumers systematically adjust their baskets of goods according to the slightest change in relative prices. All these models are highly abstract constructs that allow the 
exploration of relations between economic variables. Most of them will ultimately be put to the test, and when they are, the "metaphorical" or analogical origin of the theoretical model is immaterial: the analogical concepts involved are defined with just as much precision and technicality as the most literal ones, at least by those who take the theory seriously enough to test it. Some might claim that the results of those tests are too inconclusive to justify the development of the model, but this is quite a different matter.

More typically, in their search for fruitful analogies, economists look outside their own science towards different areas of knowledge. The paradigmatic case of such a "borrowing" is possibly that involving the adoption by marginalist economists of some conceptual structures similar to those of XIXth century energetics, documented by Mirowski in his controversial book. What is important for the present discussion is not whether marginalist economists have slavishly submitted themselves to the conceptual structure developed by physicists as Mirowski claims, but rather that they have attempted to apply analogically a mathematical conceptual apparatus which was being used in physics to economics. ${ }^{\text {xix }}$ It is because this conceptual apparatus familiar to physicists was influential in the development of economics that Klamer and Leonard describe this "borrowing" as the paradigmatic example of what they consider to be a "constitutive metaphor" (1994, p. 41). With apparent legitimacy, one who accepts Mirowski's claim can indeed see in such a process a kind of macro-metaphor, since according to this view a whole theoretical structure was applied, not without some logical violence, to a different science. Moreover, it is true that, "metaphorically" moulded into a mathematical apparatus inherited from physics in such a fashion, a theory is in a position to raise many new questions which would not have been raised had the theory been internally developed without such borrowings. ${ }^{\mathrm{xx}}$ The theoretical 
transfer between sciences creates new meanings through a process which is comparable with that at work in creative metaphors. But once a theory that has been generated in such a fashion finds a new formulation in the science which has benefited from the borrowing, it is no longer applied metaphorically to it. Whether or not it has been moulded into an apparatus inherited from physics, neoclassical theory remains a theory which pretends to explain economic behaviour by applying its categories to economic phenomena. Thus, categories generated by a so-called "metaphorical" process - which in the minds of the economists who were so fascinated by physics was very likely nothing but an explicit analogical process - do not have to be metaphorically applied to the sector for which they have been designed. ${ }^{\mathrm{xxi}}$

For the sake of illustration, let us recall that neoclassical economists do not say that economic agents maximise their potential energy, they say rather that they maximise their utility. There is no category-mistake in such a claim and this claim has to be taken literally. As we have seen, authors who have emphasised the role of economic metaphors have been exceedingly quick to detect metaphors in every term generated by analogical reasoning. For example, Klamer and Leonard ask: "on what basis did Paul Samuelson choose optimization as his heuristic metaphor over, say, satisficing or chaos?" (1994, p. 41). Even though the authors oddly illustrate their point by referring to satisficing and chaos - technical notions which evoke theories which were not yet developed when Samuelson coined his concept - their point is that he could have had in mind a concept of decision less exacting than optimisation, either a concept which requires only the attainment of a certain satisfaction or a concept which is based on random. Be that as it may, the only aspect of their view that I would like to discuss here is the idea that "optimization" should be considered a metaphor. But, why should the use of this word be understood as metaphorical? It is an abstract concept 
chosen to say that the best (optimal) situation is sought and eventually reached. Alternatively, one can describe it as a Weberian ideal-type resulting from the stylisation of a process which takes place in the real world but not in the idealised form which is evoked by the concept of optimisation. Samuelson and (possibly) other economists may have been influenced by mathematical physics when they coined the word "optimization" on the model of "maximization", but they have nonetheless managed to coin a concept that is meaningful only in a human context since nothing can be optimal that is not in relation to human values. Economic decisions but not physical processes can literally produce the best possible result. It is true that Samuelson defines optimisation in such an abstract and rigorous way that probably no human being optimises in this fashion. But when he forces the matter in this way and suggests that real people optimise, it would be odd to claim that in saying this he is committing a kind of metaphorical category-mistake since only people can optimise at all, and since many people actually do manage to optimise at least on some occasions. Here again, the concept of a metaphor has been overextended to include the abstract and idealised concept of optimisation which is in no way metaphorical. Clearly, if "literally true" implies "universally true", it is not literally true that people optimise, that people are rational, or that firms equate their marginal cost to their marginal revenue, but these banal considerations - which concern the highly abstract character of microeconomics - have hardly anything to do with metaphors. The statement "people are optimisers" is a literal statement that, depending on one's point of view, can be characterised either as approximately true or plainly false. Similarly, to say, for example, that the blackboard is flat is not strictly true since the blackboard is only approximately flat, but it is not a metaphor since flatness is a property which belongs to it in a sufficiently evident way and since there is manifestly no calculated categorymistake made in saying so. 
In spite of these considerations, though, one can understand why it might be tempting to describe optimisation as a metaphor. By adopting a variant of the idea of maximisation which was central to the theoretical apparatus of physics, economists are led to force the description of economic phenomena to fit into an elegant mathematical structure. According to Mirowski, the neoclassical theory of production has been significantly distorted because "there was no analogue of production in the energetics metaphor" (1989, p. 283). The choice by economists of a particular mathematical structure akin to one which has been highly successful in a science as prestigious as physics is presented by him as a decisive inducement to extrapolate the whole structure of the physical theory to economics and to manipulate the parameters of the concrete economic situation in such a way that they fit the structure. One who accepts such a view might be inclined to think that economists have applied to the economic world a theoretical structure borrowed from physics, in the same way that others have applied to any readily spendable money the predicate "liquid", a term borrowed from elementary hydraulics. But the difference between these two cases is obvious. In the latter, the borrowing is a typical metaphor which implied, at its origin, a calculated category-mistake through which a new concept ("liquidity") was created to replace a tedious paraphrase when it came to designating an already well-known phenomenon. In the former, the borrowing of a mathematical structure developed in another science results from a highly suggestive and potentially fruitful analogy which turned out to be very helpful in suggesting new theoretical tools. However, such theoretical tools, regardless of their origin, must be accepted or rejected on their own merits. Distortion might be a temptation, but it is surely not implied by the very fact of analogical thinking. If the theory is put to the test, it will be done just as prosaically as with any less "metaphorical" one. Suppose that a theory is designed without any influence from 
any other scientific sector and that it owes nothing to any kind of analogy. Assuming that such an autarkic theory is possible, it would meet exactly the same methodological problems as would a more "metaphorically based" theory when it comes to applying it to its domain and to deciding whether it should be accepted as true or rejected as false. There is no reason to think that the analogical origin of the latter will add specific difficulties to this already problematic methodological decision. Naturally, it is possible that theories based on attractive analogies have a greater chance of orienting the analysis in a misleading direction, but if it turns out to be the case, it is not due to the subversive effect of some metaphorical category-mistake; it is simply due to the fact that any theory which is accepted for its theoretical appeal, rather than for its empirical adequacy, has a greater chance of being misleading and deceptive.

\section{$* * *$}

The fact that reliance on analogies can, in some circumstances, be misleading and deceptive is precisely what makes critical analysis of theoretical transfers between sciences significant to the history of economic thought. The point of the present paper was not to assess or to endorse an enterprise like Mirowski's, which explicitly aim to contribute to this kind of critical analysis. However, it is difficult to deny that, if well grounded, any attempt to trace out the possible distortions in an economic theory caused by too slavishly submitting to an attractive analogy might be a fruitful result of a critical history of economic thought. As underscored by James Bernard Murphy, "all analogies have implications that can distort theory if the analogies are not subject to criticism" (Murphy, 1994, p. 543). And as illustrated by Camille Limoges and Claude Ménard's analysis of Marshall's thought, economists sometimes have to step back in order to avoid the "unbearable consequences" entailed by their adoption of structuring analogies from the natural sciences (Limoges \& Ménard, 1994, p. 349). However, this 
last case illustrates fairly well that economists are not necessarily slavishly committed to an analogy, but since it is not clear that they always "step back" in such situations, critical but careful analyses of the way metaphors and analogical transfers have influenced their thought should be particularly welcomed. The claim of this paper was that to attain the beneficial results of such critical analyses, it is in no way necessary to inflate the meaning of "metaphor" in such a way that this trope comes to be seen as pervasive and its impact decisive in economic theory. Doing so, it was argued, risks dissolving the very nature of metaphor by confusing it with any kind of logical operation just as reducing theory to simple metaphors risks stripping it of its very significance. 
i The author would like to thank Andrew Connochie, Olaf DeWinter, Yves Gingras, Bruce Maxwell, Philippe Mongin as well as Uskali Mäki and other members of the Erasmus seminar in Rotterdam for their very useful observations. He is especially grateful to the two anonymous assessors of Economics and Philosophy for their detailed and thoughtful comments. Financial assistance from the SSHRC (Ottawa) and the Fonds FCAR (Quebec) was also greatly appreciated.

ii Aristotle 1457 b 6-9: " A 'metaphor' is the application [to something] of a name belonging to something else [...]," p. 28 in Aristotle (1987). For a discussion of Aristotle's view, see Ricœur, 1977, pp. 9-43.

iii McCloskey (1985).

iv Black, 1962, p. 236; see also Black (1979); for a discussion of Black's view, see Ricœur, 1977, pp. 83-90.

v Mirowski (1989). For reviews that strongly object to the main theses of this book, see Hoover (1991) and Walker (1991).

vi For a philosophical analysis of this paradox, see Foucault (1983). Sadok (1979, p. 51), discussing a problem raised by Cohen 1971, pp. 56-57, concludes that "a sentence such as, 'This is a flower,' said while pointing to a conglomeration of pigment on canvas would be, strictly speaking, false" and attributes the nonliteralness to a "metonymical intent".

vii Klamer \& Leonard, 1994, pp. 41-42 referring to Pepper (1942).

viii In fact, it is clear that the "circulation" of money is a metaphor which is not borrowed from steam engineering since its use (according to the Oxford English Dictionary, it was already used in English in 1684) antedates the age of steam engine and it is far from clear that it was borrowed from medical language. 
However, Alborn refers explicitly to the way Victorian economists were modelling the circulation of money with the help of analogies drawn either from biology or from engineering. The "circulation" of money as such is an older metaphor which is ultimately derived from the idea of a circular movement. This point illustrates the importance (discussed in the next section) of clearly distinguishing analogical models from metaphors.

ix At most, one might claim that, since their meaning is not strictly speaking a primary and purely conventional meaning, dead metaphors are taken less literally than strictly literal utterances. They are nonetheless taken literally rather than metaphorically: indeed, they refer to a "relatively primary sense of a word" since no other term refers more directly to the specific phenomena they designate unambiguously in a given context. Klamer and Leonard (1994, p. 39) themselves seem to acknowledge the fact that most metaphors underlying economic models are "dead metaphors" (an expression which, according to them, was coined by Turbayne), but they observe that such metaphors "can be brought back to life" especially in the mind of "newcomers to economics and outsiders", an incontestable fact which, however, can hardly affect economic theory as such.

x Black, 1979, p. 26) This Blackian sense of the word "catachresis" is defined in (Black, 1962, p. 33).

xi Goodman, 1976, p. 73. The definition of a "category-mistake", which was proposed by Gilbert Ryle in a context unrelated to the question of metaphor, has been previously used (without insistence on the calculated character) to characterise metaphors by Collin Murray Turbayne (1970, p. 12 and p. 18). On this point, see Ricœur (1977, pp. 197 and 235). Philip Mirowski (1989, p. 278), 
following Mary Hesse, seems to have adopted such an interpretation in the case of a poetic metaphor.

xii As observed by Hendersen, 1998, p. 291, " 'Dead' metaphors (cliché) is the anticipated outcome of knowledge but not the anticipated outcome of poetry."

xiii Theoretical models used by economists must be distinguished from those semantic models that for logicians and philosophers of science are models of a theory interpreted through them in the sense that the axiomatic theorems of the theory are made true under this interpretation. For an illuminating illustration of the role of such models, see the first chapter of Hesse (1966) who refers to them as model1. See also Suppe, 1977, pp. 95-102.

xiv Iconic models of this type are akin to scale models (like scale models of an airplane, for example) except that - as underlined by Black (1962, pp. 222) who prefers to call them analogue models for this reason - they reproduce the structure and not the shape of what they model. Nonetheless, they must be clearly distinguished from what some philosophers of science also call "iconic" models in order to characterise any representation (like, for example, the Bohr billiard ball model of the atom) which is "structurally similar (isomorphic) to what it models" (Suppe, 1977, p. 97). This last kind of models which correspond to Hesse's model2 (Hesse, 1966, p. 10ff.) are isomorphic to the semantic models which interpret an axiomatic theory (see footnote 12 above) whereas the iconic (or analogue) models exemplified by Philips's hydraulic model are isomorphic to theoretical models of the type devised by economists. Irving Fisher (1925, pp. 24 \& ff.), for example, has constructed such an hydraulic model to represent his microeconomic theory of price based on marginal utility. For an account of this type of model, see Black, 
1962, pp. 222-223 and for an analysis of Fisher's and Phillips's respective hydraulic models, see Lagueux (1992).

xv Klamer and Leonard, 1994, p. 45, define correctly "allegory" along these lines ("a long or extended metaphor [...]"), but their definition of "analogy" ("a sustained and systematically elaborated metaphor [...]") does not allow the reader to clearly distinguish one from the other, even if they do qualify this ambiguity by saying that an analogy tends to obscure its parentage with its founding metaphor, whereas in the case of an allegory it is the other side of the original metaphor which is forgotten. By contrast, I. Bernard Cohen in the same book (1994, p. 57) insists on clearly distinguishing analogies and metaphors.

xvi Klamer and Leonard (1994, p. 45) seem to acknowledge this point in their comment on their definition of "allegory", but this does not seem to have consequences for the thesis in their paper.

xvii In reality, a reduction of the flow of money will depend of the marginal rate of substitution between goods, but most hydraulic models do not make room for multiple goods.

xviii Black (1966, pp. 219-243). See also Hesse (1966) whose last chapter was largely inspired by Black's theses. Black and Hesse raise highly interesting points which, by contrast with the present paper, concern mostly the context of discovery of a theory. A full and satisfactory discussion of their views would require a different paper, and one which would be less directly related to economics.

xix The fact that many economists have been influenced by physics, a science in which they have found, in particular, various mathematical instruments appropriate to their own analysis, is generally admitted both by the predecessors and even by the critics of Mirowski (see Hoover, 1991, p. 141 and Walker, 1991, 
p. 628). The controversy over More Heat than Light concerns mainly the nature of this influence, its alleged pervasive, systematic and exceptional character, the kind of evidence which is acceptable to document it and its significance for the development of economics both in the XIXth and XXth centuries. For a more recent account of the influence exerted by physical and mathematical models on economics, see Israel (1997).

xx This point has been usefully analysed by Cristina Bicchieri in Bicchieri (1988), even if the author does not seem to agree with the restrictions on the meaning of the word "metaphor" advocated in the present paper. The idea that mathematical formalism developed in a science can be interpreted as an analogical model to be applied to other contexts has been often discussed by philosophers of science, starting at least with Hesse (1966).

xxi Had metaphor not been given such a prominent role in recent literature, such a conclusion would have likely been considered too widely admitted among philosophers of science to be worth mentioning. 


\section{REFERENCES}

Alborn, Timothy L. 1994. `Economic man, economic machine: images of circulation in the Victorian money market'. In Mirowski (1994), pp. 173-196.

Aristotle. 1987. Poetics, translated by Richard Janko. Indianapolis, Hackett Publishing.

Bar-Hillel, Yehoshua. 1971. Pragmatics of Natural Languages. Dordrecht, D. Reidel Publishing.

Beardsley, Monroe C. 1972. 'The Metaphorical Twist'. In Shibles (1972), pp. 73-91.

Bicchieri, Cristina. 1988. 'Should a Scientist abstain from Metaphors?'. In Klamer \& Solow (1988), pp. 100-114.

Black, Max. 1962. Models and Metaphors: Studies in Language and Philosophy. Ithaca, N.Y., Cornell University Press.

Black, Max. 1979. `More about Metaphors'. In Ortony (1979), pp. 19-43.

Cartwright, Nancy. 1983. How the Laws of Physics Lie. New York, Oxford University Press.

Cohen, Bernard. 1994. 'Newton and the social sciences, with special reference to economics, or, the case of the missing paradigm'. In Mirowski (1994), pp. 55-90.

Cohen, L. Jonathan. 1971. 'Some remarks on Grice's views about the logical particles of natural language'. In Bar-Hillel (1971), pp. 50-68..

Cornell Way, Eileen, 1991. Knowledge, Representation and Metaphor. Dordrecht, Kluwer Academic Publishers.

Fisher, Irving. 1925. Mathematical Investigations in the Theory of Value and Prices. New Haven, Yale University Press.

Foucault, Michel. 1983. This is not a pipe, Berkeley and Los Angeles, University of California Press.

Goodman, Nelson. 1976. The Languages of Art. Indianapolis, Hackett Publishing. 
Hausman, Daniel. 1992. The Inexact and Separate Science of Economics. Cambridge, Cambridge University Press.

Henderson, Willie. 1998. 'Metaphor'. InThe Handbook of Economic Methodology, pp. 289-294. John Davis, Wade Hands and Uskali Mäki (eds.). Cheltenham, Edward Elgar Publishing.

Hesse, Mary. 1966. Models and Analogies in Science. Notre Dame, Indiana, University of Notre Dame Press.

Hesse, Mary. 1972. `Scientific Models'. In Shibles (1972), pp 169-180.

Hoover, Kevin D. 1991. `Mirowski's Screed: A Review of Philip Mirowski's More Heat than Light: Economics as Social Physics, Physics as Nature's Economics.' Methodus, 3: 139-145.

Israel, Giorgio. 1997. La mathématisation du réel. Paris, Le Seuil, 1997.

Klamer, A., McCloskey, D. and Solow, R. (eds.). 1988. The Consequences of Economic Rhetoric. Cambridge, Cambridge University Press.

Klamer, Arjo and Leonard, Thomas C. 1994. 'So what's an economic metaphor?'. In Mirowski (1994), pp. 20-51.

Lagueux, Maurice. 1992. 'What's Wrong with Metaphors in Economics?: the Case of Hydraulic Metaphors'. In Perspectives on the History of Economic Thought, vol VIII., pp. 35-50. Todd Lowry (ed.). Aldershot, Hants., Edward Elgar Publishing. Limoges, Camille and Ménard Claude. 1994. 'Organization and the division of labor: biological metaphors at work in Alfred Marshall's Principles of Economics'. In Mirowski (1994), pp. 336-359.

Marshall, Alfred. 1920. Principles of Economics. London, MacMillan.

McCloskey, Donald N. 1983. 'The Rhetoric of Economics'. Journal of Economic Literature, 21: 481-517. 
McCloskey, Donald N. 1985. The Rhetoric of Economics, Madison: University of Wisconsin Press.

Mirowski, Philip. 1989. More Heat than Light. Economics as Social Physics, Physics as Nature's Economics. New York, Cambridge University Press.

Mirowski, Philip (ed.). 1994. Natural Images in Economic Thought. New York, Cambridge University Press.

Murphy, James Bernard. 1994. `The kinds of order in society'. In Mirowski (1994), pp. 536-582.

Ortony, Andrew (ed.). 1979. Metaphor and Thought.. Cambridge. Cambridge University Press.

Pepper, Stephen C. 1942. World Hypotheses, A Study in Evidence. Berkeley and Los Angeles, University of California Press.

Phillips. A. William. 1950. `Mechanical Models in Economic Dynamics'. Economica, 17: 283-305.

Ricœur, Paul. 1977. The Rule of Metaphor, Multi-disciplinary Studies of the Creation of Meaning in Language. Toronto, University of Toronto Press.

Rumelhart, David E. 1979. `Some Problems with the Notion of Literal Meanings'. In Ortony (1979), pp. 78-90.

Sadok, Jerrold M. 1979. `Figurative Speech and Lingusitics'. In Ortony (1979), pp. 4663.

Searle, John R. 1979. `Metaphor'. In Ortony (1979), pp. 92-123.

Shibles, Warren (ed.). 1972. Essays on Metaphors. Whitewater, Wisconsin, Language Press.

Suppe, Frederick. 1977. The Structure of Ssientific Theories second edition. Urbana, University of Illinois Press. 
Turbayne, Collin Murray. 1970. The Myth of Metaphor. Columbia, University of South Carolina Press.

Walker, Donald. A. 1991. 'Economics as Social Physics'. The Economic Journal, 101: 615-631. 


\title{
Do Metaphors Affect Economic Theory?
}

\begin{abstract}
The paper challenges the idea that the presence of metaphors substantially modifies crucial methodological conclusions about economic analysis. After denouncing the tendency to present as a metaphor any utterance which cannot be taken in a strictly literal sense, the paper argues that most of the metaphors that one finds in economics are dead metaphors which can hardly be distinguished from plain literal language. Then, the analogies involved in theoretical transfers from other sectors of science is disentangled from purely metaphorical processes. While acknowledging that tracking metaphors in economics might be worthwhile, the paper tends to dedramatize the methodological consequences of their alleged omnipresence.
\end{abstract}




\section{Biographical Note}

Maurice Lagueux has studied economics at McGill University and philosophy at the University of Paris. He is professor of philosophy at the University of Montreal. He has published a book discussing marxism and several papers on the methodology of economics (mostly on rationality, externalities, Austrian economics and neoliberalism), the philosophy of history and the philosophy of architecture. 